\title{
Variety difference of physicochemical and cooking properties of selected brown rice from Thailand and Malaysia
}

\author{
${ }^{1}$ Chapagai, M.K., ${ }^{2}$ Wan Rosli, W.I., ${ }^{1}$ Karilla, T. and ${ }^{1, *}$ Pinkaew, S. \\ ${ }^{1}$ Department of Food Science and Nutrition, Faculty of Science and Technology, Prince of Songkla \\ University, 94000, Pattani, Thailand \\ ${ }^{2}$ School of Health Sciences, Universiti Sains Malaysia, 16150 Kubang Kerian, Kelantan, Malaysia
}

\begin{abstract}
Article history:
Received: 29 August 2019

Received in revised form: 28

November 2019

Accepted: 4 December 2019

Available Online: 29

December 2019
\end{abstract}

\section{Keywords:}

Brown rice.

Physicochemical properties,

Cooking properties,

Textural properties,

Pasting properties

DOI:

https://doi.org/10.26656/fr.2017.4(3).305

\section{Introduction}

Rice has been a staple food of half of the world's population. About $20 \%$ of total calorie is assumed to be supplied from rice alone compared to the wheat (19\%) and maize (5\%) (Shinde et al., 2014). Data shows rice consumption is about $82.5 \%$ of total production (about 496.9 million tons) globally in 2013/14 (FAO, 2014).

Rice is a popular staple food in East Asian countries including Thailand and Malaysia. Cultivation of different varieties of rice has been in practice in these regions in terms of size, color, taste and cooking properties (Norimah et al., 2008). Rice can be found in different shapes, sizes, colors, aroma with soft to hard cooking quality as well and nutritional properties (Kennedy and Burlingame, 2003). Preference of rice is seen mainly upon texture, appearance, size, aroma and nutritional values (Fitzgerald et al., 2009). The economic value of rice in terms of price is governed mainly by textural properties (Kaur et al., 2014). Compared to common staple white rice, brown rice is considered highly nutritious due to the presence of dietary fibers, vitamins, minerals and bioactive compounds (Dipti et al., 2012), however, preference is less due to its hard texture and poor cooking quality. A number of studies are focused on to prepare brown rice for improved cooking and sensory qualities such as quick-cooking brown rice (Sabularse et al., 1991), enzyme-treated rice (Watanabe et al., 1991), high pressure treated rice (Boluda-Aguilar et al., 2013). However, none of the mentioned techniques was successful to get the desired cooking quality of brown rice. Alternatively, progress has been made to achieve similar health benefits of brown rice by incorporating brown rice flours in flour-based products such as pasta, noodle, porridge, baby and geriatric foods. The physicochemical properties such as the textural properties and the pasting properties are considered important attributes of rice quality that can help to understand appropriate application of brown rice as such or in different product forms. Therefore, this study is aimed to investigate the cooking, textural and pasting properties of five varieties of brown rice sold in the Southern Thailand and the East coast of Malaysia. This study could be useful to understand the properties of the brown rice attributed to higher preference by local 
people and also for better utilization as healthy substitutes of the white rice.

\section{Materials and methods}

\subsection{Samples}

Paddies of three varieties namely Chiang $(\mathrm{CH})$, Lepnok (LP) and Sungyod (SY) grown in Phathalung rice research center, Southern Thailand and were selected and dehusked. Commercially available brown rice of two varieties, $\mathrm{LS}_{1}$, and $\mathrm{LS}_{2}$ from Malaysia were also used for this study. All the rice samples were well stored below $4^{\circ} \mathrm{C}$ in plastic bags (vacuum packed). All the samples were brought to normal temperature before carrying out analysis. The moisture content of rice was determined according to AOAC (2000). All of the following measurements were done in $\geq 3$ times (triplicate).

\subsection{Rapid visco analyser (RVA) pasting properties}

Pasting properties of the brown rice flour were determined by using RVA (RVA 4D, Newport Scientific, Australia). Three grams of sample (14\% moisture content basis) and calculated amount of distilled water was added into a canister. Rapid visco analyser with Thermocline software was used to analyse pasting properties. The heating profile was set to $50^{\circ} \mathrm{C}$ for $1 \mathrm{~min} 30 \mathrm{~s}$, increased temperature up to $95^{\circ} \mathrm{C}$ within $3 \mathrm{~min} 45 \mathrm{~s}$. The sample was kept at $95^{\circ} \mathrm{C}$ for $2 \min 30 \mathrm{~s}$ and decreased up to $50^{\circ} \mathrm{C}$ within $3 \mathrm{~min} 45 \mathrm{~s}$. Pasting properties such as peak viscosity, breakdown viscosity, trough viscosity, final viscosity, setback viscosity, peak time and peak temperature were recorded.

\subsection{Soaking characteristics}

Brown rice $(2 \mathrm{~g})$ was soaked in $25 \mathrm{~mL}$ of distilled water at room temperature $\left(34^{\circ} \mathrm{C}\right)$ and taken out after 15 , $30,60,90,120,150$ and 180 mins. After drying by paper towels, these soaked brown rice samples were weighed to estimate the amount of water uptake.

\subsection{General cooking properties of brown rice}

\subsubsection{Minimum cooking time}

Brown rice $(2 \mathrm{~g})$ was cooked in a test tube with 25 $\mathrm{mL}$ distilled water in boiling water. The minimum cooking time was taken as the time required to lose opaqueness of the endosperm of rice kernels (Singh et al., 2005).

\subsubsection{Water uptake ratio}

The water uptake ratio was determined following the method suggested by Singh et al. (2005). Brown rice (2 g) was cooked in $20 \mathrm{~mL}$ distilled water for a minimum cooking time in a boiling water bath. After draining the water, the surface of the cooked rice was dried using paper towels. The water uptake ratio was determined by dividing the weight of cooked rice to the weight of raw rice.

\subsubsection{Elongation ratio}

Elongation ratio (ER) of brown rice was determined by dividing the length of 10 cooked kernels to the 10 uncooked kernels (Singh et al., 2005).

\subsubsection{Cooked length-breadth ratio (L/B ratio)}

The cooked length-breadth ratio was determined by dividing the length of 10 cooked kernels by the breadth of the same kernels (Singh et al., 2005).

\subsubsection{Gruel solid loss}

Gruel solid loss was determined with modification of the method given by Juliano (1985). Sample (2 g) was cooked to minimum cooking time in a test tube $(20 \mathrm{~mL}$ distilled water) with a set temperature $\left(100^{\circ} \mathrm{C}\right)$. Using a strainer, the cooked rice and gruel was separated out. The gruel was dried at $105^{\circ} \mathrm{C}$ until constant weight to find the solid present.

\subsection{Textural properties}

The texture of cooked brown rice was carried out using a texture analyser (Stable Micro Systems, TA.XT.Plus, Texture Technologies Corp., UK). Texture profile analysis of cooked rice samples was carried out according to the modified method of Mohapatra and Bal (2006). The texture profile was recorded through the computer program. Brown rice of $10 \mathrm{~g}$ was cooked to minimum cooking time. About two to three cooked rice kernels used for texture analysis. A two-cycle compression force versus time program was used to compress the samples until $90 \%$ of the total strain. A 6$\mathrm{mm}$ diameter probe was used to compress the rice kernels, with pre-test and post-test speeds of $1 \mathrm{~mm} / \mathrm{sec}$ and test speed of $0.5 \mathrm{~mm} / \mathrm{sec}$. Parameters recorded from the test curves were hardness, adhesiveness, and cohesiveness. All textural analyses were replicated at least 6 times per sample.

\subsection{Calorific value}

Determination of calorific value was carried out by Bomb calorimeter (Berfungsi, IKA C 2000 model, Malaysia) method. The brown rice sample was dried at $100^{\circ} \mathrm{C}$, cooled in a desiccator and about $500 \mathrm{mg}$ was taken to make a pellet. The pellet was put inside a bomb calorimeter and that was run to analyse the calorific value in terms of $\mathrm{kcal} / \mathrm{g}$ dry weight. 


\subsection{Statistical analysis}

The data were expressed as means \pm standard deviation (SD) from all the measured data for each treatment. Data were analysed using SPSS version 20.0 (SPSS, Inc. Chicago) and MS excel 2010. The differences among average values were estimated by analysis of variance (ANOVA) and the level of significance was determined by Tukey's test at $\mathrm{p}<0.05$.

\section{Results and discussion}

\subsection{Soaking characteristics}

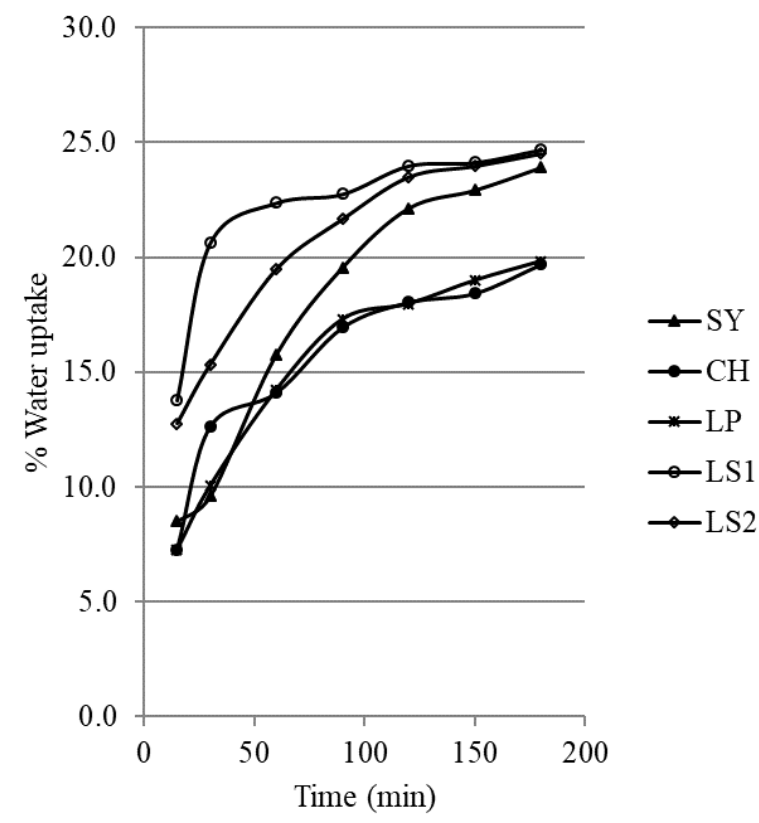

Figure 1. Soaking kinetics of five varieties of brown rice. SY: Sangyod, CH: Chiang, LP: Lepnok, $\mathrm{LS}_{1}$ : Long grain specialty $1, \mathrm{LS}_{2}$ : Long grain specialty 2.

The soaking characteristics of different brown rice are shown in Figure 1. The hydration curves showed that water absorption increased sharply for $15-30$ mins of soaking, for all varieties except for SY. Soaking resulted in up to $24 \%$ water absorption within $3 \mathrm{hrs}$. Similarly, absorption of water ranged from 17 to $21 \%$ within a period of $2 \mathrm{hrs}$ in all five varieties. Until $2 \mathrm{hrs}$ period, there was a faster rate of soaking, thereafter; comparatively slower rate (plateau) was observed (Figure 1). From the soaking kinetics, the minimum soaking period of brown rice was determined to be $2 \mathrm{hrs}$. Many studies on white rice have reported an optimum soaking period of $30 \mathrm{mins}$ to $60 \mathrm{mins}$ as plateau moisture level (Chiang and Yeh, 2002; Boluda-Aguilar et al., 2013). Soaking (at least 30 mins) before cooking results in better cooking quality (Chakkaravarthi et al., 2008). The intact bran in brown rice affects the soaking kinetics in brown rice (Han and Lim, 2009) however, soaking kinetics in polished rice entirely depends on time, temperature and solute level. A study on the hydration kinetics of milled rice showed that there was a higher rate of water absorption during the first 30 mins (Das et al., 2006). In the present study, SY (red-pigmented brown rice) was found to have slower water penetration rate compared to other varieties for the first $30 \mathrm{mins}$ however, the rate of absorption increased afterwards. Water penetration was rapid (up to $13 \%$ ) for the first 15 min in case of $\mathrm{LS}_{1}$ and $\mathrm{LS}_{2}$ unlike SY, CH, and LP (Figure 1). Pre-soaking has been found to reduce the cooking time by more than 10 mins in a study conducted using the rice cooker (Das et al., 2006).

\subsection{General cooking properties}

General cooking properties included minimum cooking time (MCT), cooked $\mathrm{L} / \mathrm{B}$ ratio, elongation ratio (ER), gruel solid loss and water uptake (WU) ratio (Table 1). The MCT of five varieties ranged from 29 to 35 mins with the highest for $\mathrm{CH}$ (35 mins) and the lowest (29 mins) for $\mathrm{LS}_{1}$. The variation in cooking time may be the difference in thickness and characteristic of the outer intact bran layer that influences the penetration of water (Wu et al., 2014). A study on the cooking of rice reported that the cuticle layer in brown rice was the primary structure leading to low water absorption, elongation of cooking time and reduction in volume expansion (Wu et al., 2014).

$\mathrm{L} / \mathrm{B}$ ratio of cooked five varieties ranged from 2.4 to 3.0. In the present study, the $\mathrm{LS}_{2}$ variety showed the highest ratio of cooked L/B. Only LP and $\mathrm{LS}_{2}$ had found significantly different $(p<0.05)$ in terms of $L / B$ ratio. All five varieties of brown rice gave WU ratio in the range of 2.5 to 3.0, where the highest WU ratio was given by $\mathrm{LS}_{1}$ variety. A significant difference $(\mathrm{p}<0.05)$ was found in the WU ratio of SY, LP, $\mathrm{LS}_{1}$, and $\mathrm{LS}_{2}$. Similarly, the ER value of all the five varieties was found in the range of 1.1 to 1.4 . There is a significant difference $(p<0.05)$ in the mean values of ER of SY and $\mathrm{LS}_{2}$.

Gruel solid loss of the five varieties was in the range of 3.2 (Lepnok) to $5.2 \%\left(\mathrm{LS}_{1}\right)$. LP showed the least leaching compared to the highest by LS1. Gruel solid loss indicates that during cooking, rice kernels gelatinize and amylose of the granules may come out of the kernels.

Cooking properties is considered to play a significant role as rice quality attribute. Cooking implies the gelatinization of starch and rate of gelatinization of brown rice is less compared to polished rice (Billiris et al., 2012). White rice having low gelatinization rate takes less than 20 mins cooking (Singh et al., 2005), however, this is not the case for brown rice in which cooking time is depended on rice (Das et al., 2008). A previous study has reported rice having higher $\mathrm{L} / \mathrm{B}$ ratio 
Table 1. Cooking properties of five varieties of brown rice

\begin{tabular}{cccccc}
\hline Variety & MCT $(\min )$ & L/B ratio & WU ratio & ER & Gruel solid loss (\%) \\
\hline SY & $34 \pm 0.0^{\mathrm{d}}$ & $2.7 \pm 0.4^{\mathrm{ab}}$ & $2.5 \pm 0.1^{\mathrm{a}}$ & $1.1 \pm 0.1^{\mathrm{a}}$ & $4.4 \pm 0.2^{\mathrm{bc}}$ \\
CH & $35 \pm 0.0^{\mathrm{e}}$ & $2.9 \pm 0.6^{\mathrm{ab}}$ & $2.5 \pm 0.1^{\mathrm{ab}}$ & $1.3 \pm 0.1^{\mathrm{ab}}$ & $4.0 \pm 0.5^{\mathrm{ab}}$ \\
$\mathrm{LP}$ & $31 \pm 0.0^{\mathrm{b}}$ & $2.4 \pm 0.3^{\mathrm{a}}$ & $2.6 \pm 0.0^{\mathrm{b}}$ & $1.3 \pm 0.1^{\mathrm{ab}}$ & $3.2 \pm 0.3^{\mathrm{a}}$ \\
$\mathrm{LS}_{1}$ & $29 \pm 0.0^{\mathrm{a}}$ & $2.9 \pm 0.3^{\mathrm{ab}}$ & $3.0 \pm 0.0^{\mathrm{d}}$ & $1.3 \pm 0.1^{\mathrm{ab}}$ & $5.2 \pm 0.7^{\mathrm{c}}$ \\
$\mathrm{LS}_{2}$ & $33 \pm 0.0^{\mathrm{c}}$ & $3.0 \pm 0.4^{\mathrm{b}}$ & $2.8 \pm 0.1^{\mathrm{c}}$ & $1.4 \pm 0.1^{\mathrm{b}}$ & $3.4 \pm 0.1^{\mathrm{ab}}$ \\
\hline
\end{tabular}

Values are mean \pm SD. Different superscript small case letters in the same column represent significance difference $(\mathrm{p}<0.05)$. MCT: minimum cooking time, L/B: length /breadth, WU: water uptake, ER: Elongation ratio, SY: Sangyod, CH: Chiang, LP: Lepnok, LS1: Long grain specialty 1, LS2: Long grain specialty 2.

gives a higher elongation ratio as well as higher WU ratio (Singh et al., 2005). It is because of the higher surface of rice kernels that help faster absorption of water in the cooking medium. Gruel solid loss is considered a factor depending upon the aging of rice (Sodhi et al., 2003). However, in the present study, gruel resulted in due to longer cooking period, and also due to leaching through disintegrated bran in the ventral surface. The gruel solid loss corresponded to the L/B ratio as seen in $\mathrm{LS}_{1}$ and Lepnok indicated that gruel increased with respect to increasing the surface area of kernels.

\subsection{Textural properties}

The textural properties of brown rice are presented in Table 2. Hardness, cohesiveness, and adhesiveness of cooked brown rice ranged from 6.75 to $15.5 \mathrm{~N}, 0.13$ to 0.16 and -0.05 to -0.25 N.Sec respectively. RedPigmented and low amylose (12.8\%) Sungyod variety showed the highest value of hardness, however, it is known that Sungyod is considerably soft in its milled form. It indicates that brown rice form of Sungyod may be hard due to its higher content of the bran layer. Malaysian $\mathrm{LS}_{1}$ had the lowest of hardness $(6.75 \mathrm{~N})$ among five varieties. Long grain varieties of intermediate amylose content are normally found popular due to soft texture and $\mathrm{LS}_{1}$ has retained that property. The considerably low hardness of $\mathrm{LS}_{1}$ is assumed due to the likely presence of thin bran layer. Similarly, there was no significant difference in cohesiveness among studied varieties. A very low and no significant difference $(p>0.05)$ was observed in adhesiveness indicated brown rice has less adhesiveness. It might be due to slippery bran of rice. Milled rice is reported to be high in adhesiveness. A study on rice reported amylose influenced on hardness, cohesiveness, and adhesiveness. A recent study also reported that the aleurone layer and cuticle layer significantly enhanced the hardness and decreased the adhesiveness of cooked rice (Wu et al., 2014).

Table 2. Textural properties of five varieties of cooked brown rice varieties

\begin{tabular}{cccc}
\hline Brown rice & Hardness (N) & Cohesiveness & $\begin{array}{c}\text { Adhesiveness } \\
(\mathrm{N} . \mathrm{Sec})\end{array}$ \\
\hline $\mathrm{CH}$ & $11.16 \pm 4.49^{\mathrm{ab}}$ & $0.15 \pm 0.03^{\mathrm{a}}$ & $-0.05 \pm 0.07^{\mathrm{a}}$ \\
$\mathrm{SY}$ & $15.50 \pm 5.16^{\mathrm{b}}$ & $0.16 \pm 0.02^{\mathrm{a}}$ & $-0.25 \pm 0.27^{\mathrm{a}}$ \\
$\mathrm{LP}$ & $8.18 \pm 3.02^{\mathrm{a}}$ & $0.13 \pm 0.05^{\mathrm{a}}$ & $-0.17 \pm 0.16^{\mathrm{a}}$ \\
$\mathrm{LS}_{1}$ & $6.75 \pm 5.75^{\mathrm{a}}$ & $0.16 \pm 0.05^{\mathrm{a}}$ & $-0.18 \pm 0.05^{\mathrm{a}}$ \\
$\mathrm{LS}_{2}$ & $9.91 \pm 5.07^{\mathrm{ab}}$ & $0.15 \pm 0.04^{\mathrm{a}}$ & $-0.24 \pm 0.05^{\mathrm{a}}$ \\
\hline
\end{tabular}

Values are mean \pm SD. Different superscript small case letters in the same column indicate significant difference $(\mathrm{p}<0.05)$. SY: Sangyod, CH: Chiang, LP: Lepnok, LS1: Long grain specialty 1, LS2: Long grain specialty 2.

\subsection{Pasting properties}

The pasting properties of five brown rice varieties analysed by RVA are presented in Table 3. A significantly low pasting temperature of LP $\left(84.8^{\circ} \mathrm{C}\right)$ indicated a low gelatinization temperature of LP compared to the rest varieties. The low and high pasting temperature was used to adjust the cooking time (Bap, 2008). Peak viscosity ranged from 1254 (SY) to $1569 \mathrm{cP}$ $\left(\mathrm{LS}_{2}\right)$. Peak viscosity is the indication of the degree of the swelling capacity of starch during cooking (Choi et al., 2012).

The breakdown viscosity (BD) was in the range of 48 to $440 \mathrm{cP}$. The highest value of BD was seen in the case of Lepnok and the lowest for $\mathrm{CH}$. The low value of breakdown viscosity indicated that $\mathrm{CH}$ could make

Table 3. Pasting properties of five varieties of brown rice by RVA

\begin{tabular}{cccccccc}
\hline \multirow{2}{*}{ Variety } & \multicolumn{5}{c}{ Viscosity (cP) } & Peak time & Pasting \\
& \cline { 2 - 6 } & Peak & Trough & Breakdown & Final & Setback & Temp $\left({ }^{\circ} \mathrm{C}\right)$ \\
\hline CH & $1490 \pm 28^{\text {bc }}$ & $1443 \pm 3^{\mathrm{c}}$ & $48 \pm 18^{\mathrm{a}}$ & $4157.0 \pm 31^{\mathrm{d}}$ & $2714 \pm 7^{\mathrm{d}}$ & $5.82 \pm 0.5$ & $88.0 \pm 0.0^{\mathrm{c}}$ \\
$\mathrm{SY}$ & $1254 \pm 13^{\mathrm{a}}$ & $1144 \pm 1^{\mathrm{b}}$ & $110 \pm 2^{\mathrm{b}}$ & $2563.7 \pm 21^{\mathrm{a}}$ & $1419 \pm 12^{\mathrm{a}}$ & $5.29 \pm 0.1$ & $86.4 \pm 0.0^{\mathrm{b}}$ \\
LP & $1452 \pm 25^{\mathrm{b}}$ & $1012 \pm 7^{\mathrm{a}}$ & $440 \pm 33^{\mathrm{d}}$ & $2754.0 \pm 46^{\mathrm{b}}$ & $1742 \pm 39^{\mathrm{b}}$ & $5.57 \pm 0.5$ & $84.8 \pm 0.3^{\mathrm{a}}$ \\
$\mathrm{LS}_{1}$ & $1550 \pm 34^{\text {cd }}$ & $1161 \pm 3^{\mathrm{b}}$ & $389 \pm 10^{\text {cd }}$ & $3697.0 \pm 64^{\mathrm{c}}$ & $2536 \pm 30^{\mathrm{c}}$ & $5.49 \pm 0.0$ & $88.1 \pm 0.1^{\mathrm{c}}$ \\
$\mathrm{LS}_{2}$ & $1569 \pm 23^{\mathrm{d}}$ & $1187 \pm 4^{\mathrm{b}}$ & $382 \pm 19^{\mathrm{c}}$ & $3755.0 \pm 81^{\mathrm{c}}$ & $2568 \pm 52^{\mathrm{c}}$ & $5.46 \pm 0.1$ & $88.0 \pm 0.1^{\mathrm{c}}$ \\
\hline
\end{tabular}

SY: Sangyod, CH: Chiang, LP: Lepnok, LS1: Long grain specialty 1, LS2: Long grain specialty 2. 
comparatively more stable hot paste than rest brown rice flours. Setback viscosity was in the range of 1419 to $2714 \mathrm{cP}$. Significantly lower setback value of SY and the highest of $\mathrm{CH}$ was seen, and this property reflects the lower and higher retrogradation properties respectively. Setback viscosity is a result of rearrangement of gelatinized starch granules (retrogradation) resulting in final viscosity (Choi et al., 2012). The final viscosity was found in the range 2564 to $4157 \mathrm{cP}$. The highest and the lowest final viscosity was found for $\mathrm{CH}$ and SY respectively. In the cooked form, the pasting behaviour of the rice flour is reflected by final viscosity. Due to the high final viscosity as seen by RVA, $\mathrm{CH}$ would give viscous paste in comparison to other rice varieties. The peak time of the $\mathrm{CH}, \mathrm{SY}, \mathrm{LP}, \mathrm{LS}_{1}$ and $\mathrm{LS}_{2}$ samples was in decreasing order. The highest peak time of $\mathrm{CH}$ indicated that gelatinization occurred slowly to reach peak viscosity. The amount of bran layer present on kernel could be the decisive factor for such a prolonged peak time. It was observed that pasting temperature was higher for the brown rice flour which had high peak time. Characteristics of raw rice flour are elucidated which clearly showed uniformity of patterns such as peak-time from $5-6$ mins.

\subsection{Calorific value}

The calorie content of different brown rice varieties is presented in Table 4. Gross energy measured by bomb calorimeter ranged from $413.3-432.2 \mathrm{kcal} / 100 \mathrm{~g}$. The lowest calorific value was found in LP and the highest in SY. The total calorie content of SY was not significantly different from $\mathrm{CH}(426.2 \mathrm{kcal} / 100 \mathrm{~g})$ at $\mathrm{p}>0.05$; however, LP, $\mathrm{LS}_{1}$, and $\mathrm{LS}_{2}$ were significantly different $(p<0.05)$. On comparison of energy by using the Atwater factor and bomb method, a difference of maximum $(26 \%)$ was found in the case of $\mathrm{CH}$.

Table 4. Calorific values of raw brown rice by bomb method and compare with Atwater factor calculation

\begin{tabular}{cccc}
\hline \multirow{2}{*}{ Variety } & \multicolumn{3}{c}{ Calorific values (Kcal/100 g) } \\
\cline { 2 - 4 } & $\begin{array}{c}\text { Net energy } \\
\text { (Atwater factor ) }\end{array}$ & $\begin{array}{c}\text { Gross energy } \\
\text { (Bomb method) }\end{array}$ & \% difference \\
\hline SY & 325.5 & $432.2 \pm 4.3^{\mathrm{c}}$ & 24.7 \\
CH & 313.6 & $426.2 \pm 21.6^{\mathrm{bc}}$ & 26.4 \\
LP & 334.2 & $413.3 \pm 16.6^{\mathrm{a}}$ & 19.1 \\
$\mathrm{LS}_{1}$ & 340.2 & $424.4 \pm 45.0^{\mathrm{b}}$ & 19.8 \\
$\mathrm{LS}_{2}$ & 333.7 & $423.1 \pm 8.4^{\mathrm{b}}$ & 21.1 \\
\hline
\end{tabular}

Values are mean $\pm \mathrm{SD}$. Different superscripts within the same row are significantly different $(\mathrm{p}<0.05)$. SY: Sangyod, $\mathrm{CH}$ : Chiang, LP: Lepnok, LS1: Long grain specialty 1, LS2: Long grain specialty 2 .

\section{Conclusion}

Physicochemical and cooking properties of five brown rice varieties were investigated. Hydration kinetics showed soaking can be used to reduce the cooking time. Different cooking times among varieties have an influence on the cooking properties such as cooked L/B ratio, water uptake ratio, elongation ratio, and gruel solid loss. The energy value of brown rice varieties determined from bomb calorimeter was higher than energy calculated based on Atwater factor. The textural hardness of different varieties varied significantly. Pasting properties revealed some varieties could give stable hot paste or soft gel or hard gel due to its varying physicochemical properties. On the basis of physicochemical and cooking properties, brown rice of different varieties could be used for different purposes, for example, cooking as such in cooked kernel form or flours.

\section{Conflict of Interest}

The authors declare no conflict of interest.

\section{Acknowledgments}

SAT-ASEAN Research Fund 2013 (SAT-ASEAN 5603), Faculty of Science and Technology, Prince of Songkla University, Pattani Campus, Thailand supported this research and also partially by graduate research support from graduate school, Prince of Songkla University, Thailand. We would like to thank to Phatthalung Rice Research Centre, Phatthalung for providing brown rice samples.

\section{References}

AOAC. (2000). Official methods of analysis of the association of official analytical chemist. $17^{\text {th }}$ ed. AOAC International, Maryland, USA.

Bap, J.S. (2008). Accurate measurement of pasting temperature by the rapid visco-analyser: a case study using rice flour. Rice Science, 15(1), 69-72. https:// doi.org/10.1016/S1672-6308(08)60022-0

Billiris, M.A., Siebenmorgen, T.J., Meullenet, J.F. and Mauromoustakos, A. (2012). Rice degree of milling effects on hydration, texture, sensory and energy characteristics. Part 1 Cooking using excess water. Journal of Food Engineering, 113(4), 559-568. https://doi.org/10.1016/j.jfoodeng.2012.07.005

Boluda-Aguilar, M., Taboada-Rodríguez, A., LópezGómez, A., Marín-Iniesta, F. and Barbosa-Cánovas, G.V. (2013). Quick cooking rice by high hydrostatic pressure processing. LWT - Food Science and Technology, 51(1), 196-204. https://doi.org/10.1016/ j.lwt.2012.09.021

Chakkaravarthi, A., Lakshmi, S., Subramanian, R. and Hegde, M. (2008). Kinetics of cooking unsoaked and 
presoaked rice. Journal of Food Engineering, 84(2), 181-186.

j.jfoodeng.2007.02.061

https://doi.org/10.1016/

Chiang, Y. and Yeh, A. (2002). Effect of soaking on wet -milling of rice. Journal of Cereal Science, 35(1), 85 -94. https://doi.org/10.1006/jcrs.2001.0419

Choi, I., Han, O., Chun, J., Kang, C., Kim, K., Kim, Y., Cheong, Y., Park, T., Choi, J. and Kim, K. (2012). Hydration and Pasting Properties of Oat ( Avena sativa ) Flour. Preventive Nutrition and Food Science, 17, 87-91. https://doi.org/10.3746/ pnf.2012.17.1.087

Das, T., Subramanian, R., Chakkaravarthi, A., Singh, V., Ali, S.Z. and Bordoloi, P.K. (2006). Energy conservation in domestic rice cooking. Journal of Food Engineering, 75(2), 156-166. https:// doi.org/10.1016/j.jfoodeng.2005.04.005

Dipti, S.S., Bergman, C., Indrasari, S.D., Herath, T., Hall, R., Lee, H., Habibi, F., Bassinello, P.Z., Graterol, E., Ferraz, J.P. and Fitzgerald, M. (2012). The potential of rice to offer solutions for malnutrition and chronic diseases: Rice, 5, 16.https:// doi.org/10.1186/1939-8433-5-16

FAO. (2014). Food Outlook: Biannual Report On Global Food Markets. Rome: Italy.

Fitzgerald, M.A., McCouch, S.R. and Hall, R.D. (2009). Not just a grain of rice: the quest for quality. Trends in Plant Science, 14(3), 133-139. https:// doi.org/10.1016/j.tplants.2008.12.004

Han, J.A. and Lim, S.T. (2009). Effect of presoaking on textural, thermal and digestive properties of cooked brown rice. Cereal Chemistry, 86(1), 100-105. https://doi.org/10.1094/CCHEM-86-1-0100

Juliano, B.O. (Ed.). (1985). Criteria and tests for rice grain qualities. In Rice: Chemistry and Technology, p. 443-513. Minnesota, USA: American Association of Cereal Chemists

Kaur, S., Panesar, P.S., Bera, M.B. and Kumari, S. (2014). Physicochemical, textural, pasting, and in vitro digestion properties of some basmati and nonbasmati rice cultivars. International Journal of Food Properties, 17(5), 1055-1066. https:// doi.org/10.1080/10942912.2011.642444

Kennedy, G. and Burlingame, B. (2003). Analysis of food composition data on rice from a plant genetic resources perspective. Food Chemistry, 80(4), 589596. https://doi.org/10.1016/S0308-8146(02)00507-1

Mohapatra, D. and Bal, S. (2006). Cooking quality and instrumental textural attributes of cooked rice for different milling fractions. Journal of Food Engineering, 73(3), 253-259. https:// doi.org/10.1016/j.jfoodeng.2005.01.028
Norimah, A.K., Safiah, M., Jamal, K., Siti, H., Zuhaida, H., Rohida, S., Fatimah, S., Siti, N., Poh, B.K., Kandiah, M., Zalilah, M.S., Wan Manan, W.M., Fatimah, S. and Azmi, M.Y. (2008). Food consumption patterns: Findings from the Malaysian Adult Nutrition Survey (MANS). Malaysian Journal of Nutrition, 14(1), 25-39.

Sabularse, V.C., Liuzzo, J.A., Rao, R.M. and Grodner, R.M. (1991). Cooking Quality of Brown Rice as Influenced by Gamma Irradiation, Variety and Storage. Journal of Food Science, 56(1), 96-98. https://doi.org/10.1111/j.1365-2621.1991.tb07984.x

Shinde, Y.H., Vijayadwhaja, A., Pandit, A.B. and Joshi, J.B. (2014). Kinetics of cooking of rice: A review. Journal of Food Engineering, 123, 113-129. https:// doi.org/10.1016/j.jfoodeng.2013.09.021

Singh, N., Kaur, L., Singh Sodhi, N. and Singh Sekhon, K. (2005). Physicochemical, cooking and textural properties of milled rice from different Indian rice cultivars. Food Chemistry, 89(2), 253-259. https:// doi.org/10.1016/j.foodchem.2004.02.032

Sodhi, N. S., Singh, N., Arora, M. and Singh, J. (2003). Changes in physico-chemical, thermal, cooking and textural properties. Journal of Food Processing Preservation, 27(5), 387-400. https:// doi.org/10.1111/j.1745-4549.2003.tb00525.x

Watanabe, M., Arai, E., Honma, K. and Fuke, S. (1991). Improving the Cooking Properties of Aged Rice Grains by Pressurization and Enzymatic Treatment. Agricultural and Biological Chemistry, 55(11), 2725 -2731. https://doi.org/10.1271/bbb1961.55.2725

Wu, J., Chen, J., Liu, W., Liu, C., Zhong, Y., Luo, D., Li, Z. and Guo, X. (2014). Effects of aleurone layer on rice cooking: A histological investigation. Food Chemistry, 191, 28-35. https://doi.org/10.1016/ j.foodchem.2014.11.058 